\title{
Air Gap Magnetic flux Optimization of Halbach Permanent Magnet Motor
}

\author{
Xinsheng Zhan*, Zhi Ji and Xiping Bao \\ School of Mechanical and Electrical engineering, Xuzhou College of Industrial Technology, Xiangwang Road No.1, Xuzhou \\ 221140, China \\ *Corresponding author
}

\begin{abstract}
This paper built a finite element model of the Halbach permanent magnet motor, whose accuracy was verified by comparing the output phase back-electromotive force of the model with that of the prototype motor. Keeping other parameters constant as far as possible, we investigated five variables one by one to find out the law how these variables affect air gap magnetic flux, which is a basis for further optimization research. After a new variable named Cost constructed to reflect the distortion ratio of air gap magnetic flux, this paper performed some optimization experiments by studying five parameters of the motor using Taguchi Algorithm, Genetic Algorithm and Pattern Search Algorithm. On the basis of summarizing the advantages and disadvantages of these Algorithms, we proposed two kinds of novel hybrid optimization Algorithms, which are named as Taguchi-Pattern Search Algorithm and Genetic-Pattern Search Algorithm, and proved the validity and practicability by experiments and finite element calculations.
\end{abstract}

Keywords- halbach array; permanent magnet motor; finite element method; genetic algorithm; taguchi algorithm; pattern search algorithm

\section{INTRODUCTION}

Compared with common induction motor, permanent magnet motor has the advantages of higher efficiency and higher power factor, so its application is more and more widely [1]. But in low speed, light load and some special occasions, there are still some problems, such as torque ripple, low efficiency and so on [2], needed to further improve. Motor optimization is a technique that can be used to improve one or more performances of motor by changing its parameters under certain constraints. Simple motor optimization is performed according to one performance, often expressed as the maximum or minimum problem which can be solved by analyzing the relationship between parameters and the performance generally. However, the problems are quite complicated and needed to apply optimization algorithm to solve if there are several constraints and variables involved, especially they are influenced mutually.

Traditional optimization algorithms are based on classical extreme theories and traditional random search algorithms[3], including all kinds of analytic algorithms, numerical algorithms and direct search algorithms such as Differential Algorithm, Lagrange Algorithm, Newton Algorithm , Interpolation Algorithm, Hooke-Jeeves Algorithm, Powell Algorithm and so on $[4,5]$.The algorithms of constrained optimization contain a variety of penalty function algorithms and direct algorithms, including SUMT Algorithm, ALAPT Algorithm, Gradient Projection Algorithm, Zigzag Algorithm and so on[6,7].In recent years, some new optimization algorithms, such as Simulated Annealing, Tabu Search, Immune Algorithm and Particle Swarm Algorithm, have been presented. All these algorithms have been applied in optimization of motor, but there are still some defects. Some algorithms are fast but sensitive to initial point, and vulnerable to get different results from different initial points [8,9].Some depend on partial derivative or partial difference quotient while the optimization models of the motor are often unable to calculate derivative or its independent variable region is not continuous. Others have to be improved due to the uncertainty of the optimization efficiency, showing high efficiency in some parts but low in the others [10,11]. Halbach motor is a kind of special high performance permanent magnet motor, whose stators are basically as same as that of induction motor, but with more variable rotor forms. Additionally, on account of the characteristics of permanent magnetic material, the theoretical basis and research methods of Halbach motors differ from those of ordinary electric excitation motors, and ordinary optimization algorithms are difficult to provide satisfactory results while some new algorithms muse to be studied.

\section{OPTIMIZATION MODEL}

As to motor optimization, it is actually a multi-variable, multi-objective, constrained complex extreme problem [12]. The performance index of the motor can be defined as Eq.(1), where $\mathrm{x}_{1}, \mathrm{x}_{2} \ldots \mathrm{x}_{\mathrm{n}}$ are the structure parameters of motor and $\mathrm{m}$ is the number of constraints.

$$
\left\{\begin{array}{c}
g_{1}(X)=g_{1}\left(x_{1}, x_{2}, \cdots, x_{n}\right) \leq 0 \\
g_{2}(X)=g_{2}\left(x_{1}, x_{2}, \cdots, x_{n}\right) \leq 0 \\
\cdots \cdots \\
g_{m}(X)=g_{m}\left(x_{1}, x_{2}, \cdots, x_{n}\right) \leq 0
\end{array}\right.
$$

The optimization objectives of the motor such as efficiency and cost can be expressed as Eq. (2).

$$
f(x)=f\left(x_{1}, x_{2} \cdots x_{n}\right)
$$


The mathematical model of the motor is shown as Eq. (3), where $\mathrm{n}$ is the number of variables, $\mathrm{m}$ is the number of constraints, $\mathrm{X}$ is variable to be optimized, $f(X)$ is the objective function and $g_{j}(X)$ is constraint.

$$
\left\{\begin{array}{c}
\min f(X), X \in R^{n} \\
g_{j}(X) \leq 0, j=1,2, \cdots, m
\end{array}\right.
$$

For permanent magnet motors, the air gap magnetic flux is a representative which can affect the performance of the motor in many aspects. Two characteristic variables can be obtained after Fast Fourier Transformation (FFT) of air gap magnetic flux, one is distortion ratio and the other is fundamental wave amplitude. But Ansoft Maxwell 15 software is unable to call FFT function to optimize the search automatically. In order to solve this problem, a new variable need to be constructed which can reflects the distortion ratio of the air gap magnetic flux with the fundamental amplitude as the constraint.

$$
K=\frac{\sqrt{\left[\frac{4}{T \sqrt{2}} \int_{0}^{\frac{T}{2}} B_{\rho} \sin (p \varphi) d l\right]^{2}+\left[\frac{4}{T \sqrt{2}} \int_{0}^{\frac{T}{2}} B_{\rho} \cos (p \varphi) d l\right]^{2}}}{\sqrt{\frac{2}{T} \int_{0}^{\frac{T}{2}} B_{\rho}^{2} d l}}
$$

In Eq.(4): $B$ is radial air gap magnetic flux density, $B_{\rho}=B_{x} \cos \varphi+B_{y} \sin \varphi$

, $P$ is number of pole pairs, $T$ is length of unit period arc which corresponds to a pole in the finite element model, $T=\int_{0}^{l} 2 d l$ and the unit is meter. Make a variable named Cost shown in Eq.(5)

$$
\text { Cost }=\sqrt{1-k^{2}}
$$

After calculation, in Eq.(4) we find that $\mathrm{K}$ is 1 in sinusoidal magnetic flux, and $\mathrm{K}$ is less than 1 in non sinusoidal ones. This shows that the more close to 1 Cost is, the more great distortion ratio of magnetic flux is, while the more close to 0 , the more small. So the objective function can be set as Cost with small as optimization direction.

\section{HALBACH ARRAY AND HALBACH Motor}

In 1979, Klaus Halbach of Lawrence Berkeley National Laboratory (LBNL) in the United States proposed a special arrangement of magnets, called Halbach array [13]. It was originally used in particle accelerator, but because of its excellent characteristics, it has been paid more and more attention in motor fields. The magnetic flux distribution of the linear Halbach array calculated by the finite element method is shown in Figure 1. Linear Halbach array is connected head to tail to form Annular Halbach array, According to the direction of bending, there are two types of annular Halbach arrays shown in Figure 2, which are inner magnetic flux enhanced and external magnetic flux enhanced.

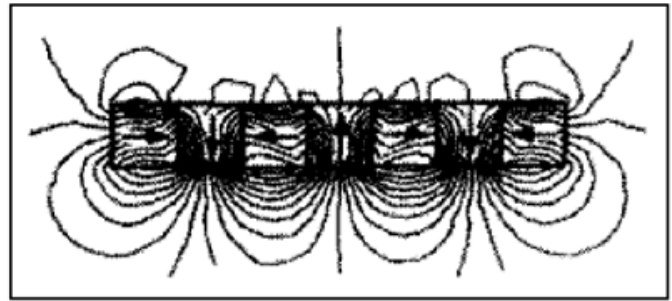

FIGURE I. MAGNETIC FLUX OF LINEAR HALBACH ARRAY[14]

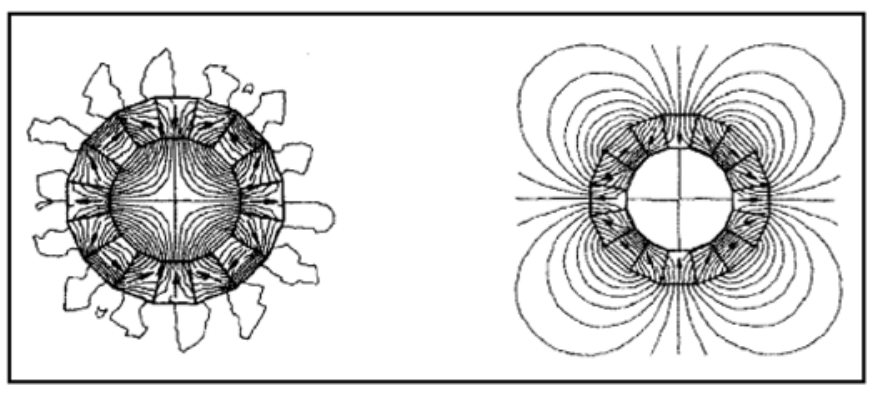

A) INNER MAGNETIC FLUX ENHANCED B) EXTERNAL MAGNETIC FLUX ENHANCED

FIGURE II. MAGNETIC FLUX OF ANNULAR HALBACH ARRAY[14]

Halbach array has two important properties. The first is magnetic monopole characteristic. From Figure 1 and Figure 2, we can see the magnetic flux of Halbach array is very strong in one side, but is quite weak in the other side, this kind of characteristic is called magnetic monopole. Literature[15] made a comparative research, and found that the amplitude of magnetic flux density in strong side and weak side of Halbach array in the distance of $0.25 \mathrm{~mm}$ from the magnet is 0.52 and 1.50 times of that of normal linear radial array in the case of other same conditions. The second is sinusoidal magnetic flux in strong side. In literature [16], after calculation it was found that magnetic flux is approximately sinusoidal and very different with that of an ordinary radial linear array, containing 5 order and 9 order harmonic and so on, but no 3 order, 7 order harmonic and so on.

Halbach motor is a special kind of permanent magnet motor whose permanent magnet arranged in according with the arrangement law of the Halbach array. In Figure 3, each magnetic pole is made up of 3 permanent magnets with a partition between the poles for positioning. $R_{S}$ is stator internal radius, $R_{m}$ is permanent magnet external radius and $R_{r}$ is rotor external radius. Magnetization angle $\beta$ is the angle between the magnetization directions of the adjacent permanent magnets in a same pole. $\alpha$ is polar angle, that is the central angle of each permanent magnet [18].

Halbach array has higher magnetic flux density, which can make all these are possible, such as larger air gap, non ferromagnetic material or hollow structure rotor. In addition Halbach array is conducive to improve the sinusoidal property of magnetic flux, and weaken cogging torque. All of these make it possible of improving dynamic performance, increasing energy density and reducing loss of motor [19]. 
(A)

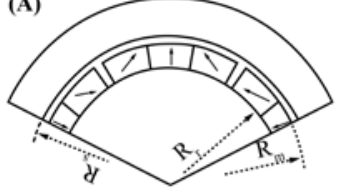

A) STRUCTURE OF MAGNETIC POLE ANGLE AND POLAR ANGLE

FIGURE III. GEOMETRY STRUCTURE OF HALBACH MOTOR[17]

\section{Air Gap Magnetic Flux Optimization}

In theory, any parameters can be selected as optimization variables, but generally speaking it should be according to optimization objectives [20]. The principles mainly considered are shown as following, 1) The objective function is significantly influenced by the variables to be optimized. 2) The number of variable should be appropriate. Too few will affect the optimization results, while too many will drop optimization efficiency. 3) Each variable should be independent, and can't influence each other. 4) Some parameters must be in accordance with the defined specifications, such as wire diameter, silicon steel sheet thickness, etc.

The prototype motor to be optimized is a 110 st- $02020 \mathrm{~h}$ permanent magnet motor with a star winding, non-oriented silicon steel sheet(DW465_50) stator, and a surface mounted rotor with three pieces of sintered $\mathrm{NdFeB}$ magnets(N35SH) each pole. According to the principles above, we fixed the permanent magnet motor inner and outer diameter of rotor and stator, winding form, number of pole pairs and slot number as constant, and selected Magnetization angle $\beta$, Pole arc coefficient emb, pole angle ratio $k$, air gap length $t$ and permanent magnet thickness thk as variables to be optimized in this paper. The measured values of these variables are shown in Table 1, which is the initial point. In optimization progress the reasonable scope of parameters must be determined according to the reference, calculation and experiments [21].

Based on the parameters above, in Ansoft Maxwell 15 software a parametric element model was constructed to compute the performance of the motor design to evaluate the algorithms [22,23], which shown in Figure 4. In order to ensure the accuracy of the model, the output phase back-electromotive force of the model and the measured value of the prototype motor was compared. If it is found that the error is too large, the model must be adjusted, until two waveforms are basically consistent.

TABLE I. TABLE.1 MEASURED VALUES OF THE PROTOTYPE MOTOR

\begin{tabular}{|c|c|c|c|c|c|c|c|c|}
\hline $\begin{array}{c}\text { Para- } \\
\text { meters }\end{array}$ & $\begin{array}{c}\text { B } \\
\text { (deg } \\
\text { ) }\end{array}$ & $\begin{array}{c}\text { em } \\
b\end{array}$ & $\mathrm{k}$ & $\begin{array}{c}\mathrm{T} \\
(\mathrm{mm} \\
)\end{array}$ & $\begin{array}{c}\text { Thk } \\
\text { (mm } \\
\text { ) }\end{array}$ & Cost & $\begin{array}{l}\mathrm{Kb} \\
(\%)\end{array}$ & $\begin{array}{c}\mathrm{B} \\
(\mathrm{T})\end{array}$ \\
\hline $\begin{array}{c}\text { Initial } \\
\text { point }\end{array}$ & $\begin{array}{c}45.0 \\
0\end{array}$ & $\begin{array}{c}0.8 \\
7\end{array}$ & $\begin{array}{c}1.0 \\
0\end{array}$ & 2.00 & 3.50 & $\begin{array}{c}0.15 \\
51\end{array}$ & $\begin{array}{c}16.55 \\
99\end{array}$ & $\begin{array}{c}0.73 \\
23\end{array}$ \\
\hline
\end{tabular}

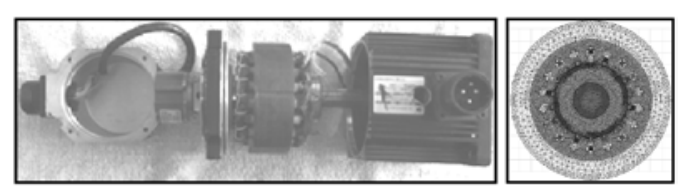

FIGURE IV. PROTOTYPE MOTOR AND FINITE ELEMENT MODEL

\section{A. The Scope of the Variables to be Optimized}

Under the premise of keeping other parameters constant as far as possible, the five variables mentioned above to be optimized was investigated one by one in order to find out the influence law on air gap magnetic flux, which is a basis for further optimization.

\section{1) Air Gap Length}

When air gap length was equal to $0.25 \mathrm{~mm}, 0.5 \mathrm{~mm}, 1 \mathrm{~mm}$, $1.5 \mathrm{~mm}, 2 \mathrm{~mm}, 2.5 \mathrm{~mm}, 3 \mathrm{~mm}, 3.5 \mathrm{~mm}, 4 \mathrm{~mm}, 4.5 \mathrm{~mm}, 5 \mathrm{~mm}$, keeping magnetization angle be equal to $45 \mathrm{deg}$ and other parameters constant, the air gap magnetic flux of the prototype motor was simulated, and the results shown in Figure 5. Both the fundamental amplitude and distortion ratio of air gap magnetic flux decrease, then gradually slows down with air gap length increasing, It can be seen from the results that effect of air gap length on air gap magnetic flux for Halbach motor is as same as that for traditional permanent magnet motor. Considering the fundamental amplitude, distortion ratio and the manufacturing process, it is more appropriate with air gap length be equal to $2 \sim 3 \mathrm{~mm}$.

\section{2) Permanent Magnet Thickness}

When permanent magnet thickness was equal to $0.5 \mathrm{~mm}, 1 \mathrm{~mm}, 1.5 \mathrm{~mm}, 2.5 \mathrm{~mm}, 3.5 \mathrm{~mm}, 4.5 \mathrm{~mm}, 5.5 \mathrm{~mm}, 6.5 \mathrm{~mm}$, keeping other parameters constant, the simulation results were shown in Figure 6. We can find that the fundamental amplitude of air gap magnetic flux increases with permanent magnet thickness increasing. The distortion ratio of the air gap magnetic flux decreases rapidly with the increase of thickness when the thickness is relatively thin, and it increases slightly after the minimum reaches $4 \mathrm{~mm} \sim 5 \mathrm{~mm}$. So it is appropriate when permanent magnet thickness is $2 \sim 3 \mathrm{~mm}$, considering the fundamental amplitude, distortion ratio and permanent magnet consumption.

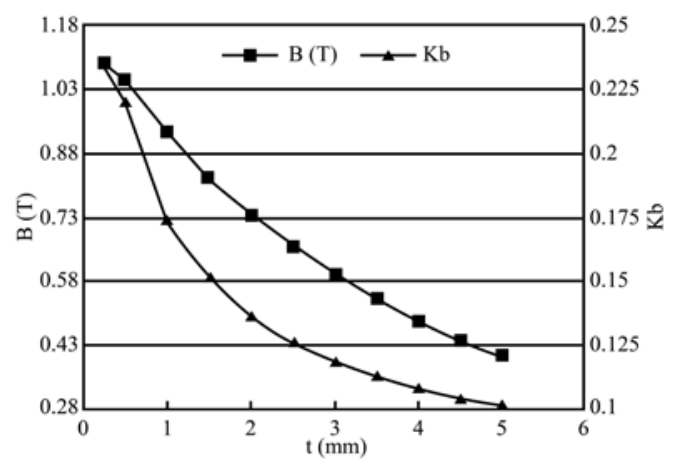

FIGURE V. EFFECT OF AIR GAP LENGTH ON AIR GAP MAGNETIC FLUX 


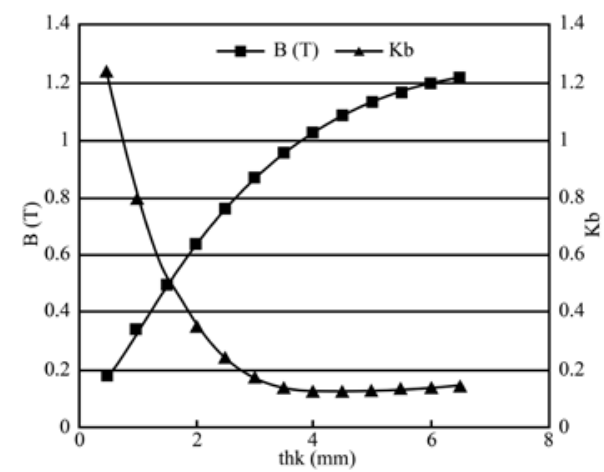

FIGURE VI. EFFECT OF PERMANENT MAGNET THICKNESS ON AIR GAP MAGNETIC FLUX

\section{3) Pole Arc Coefficient}

The simulation results were shown in figure 7 without changing any other parameters when pole arc coefficient was equal to $0.6,0.65,0.7,0.75,0.8,0.85,0.9,0.95,0.99,1$ respectively. It shows that the fundamental amplitude of air gap magnetic flux increases with the increase of pole arc coefficient, while the distortion ratio decreases, which is minimum when pole arc coefficient is $0.9 \sim 1$, and then increases slightly, so this area is the reasonable value range of the pole arc coefficient of the prototype motor.

\section{4) Pole Angle Ratio}

For Halbach motor with three permanent magnets, the center magnet is called main pole, while the other two are auxiliary poles. Pole angle ratio is defined as the ratio of main pole angle and auxiliary pole angle in the case of the same total pole angle of each pole, so it is independent with the consumption of permanent magnet, but describes the composition of pole flux. For example, the greater pole angle ratio is, the greater main pole flux is. Keeping the rest parameters of the prototype motor constant, we can get the simulation results in the case of pole angle ratio is $0.36,0.51,0.68,0.87,1.00,1.09,1.34,1.64,2.00,2.44,2.98,3.68,4.6$ $1,5.90$ respectively. The Effects of the pole angle ratio on air gap magnetic flux was shown in Figure 8 when permanent magnet thickness was $3.5 \mathrm{~mm}$ and $6 \mathrm{~mm}$. It shows, 1 ) With the increase of pole angle ratio, the fundamental amplitude of air gap magnetic flux increases rapidly. When the magnet is thin, this trend is increasing monotonically. While the magnet is thicker, it first increases and then gradually slows down. 2) With the increase of pole angle ratio, the distortion ratio decreases rapidly, and then increases quickly after reaching the minimum value. Therefore, the selection of pole angle ratio is mainly considered to minimize the distortion ratio, and it is better in the vicinity of 1 for the prototype motor.

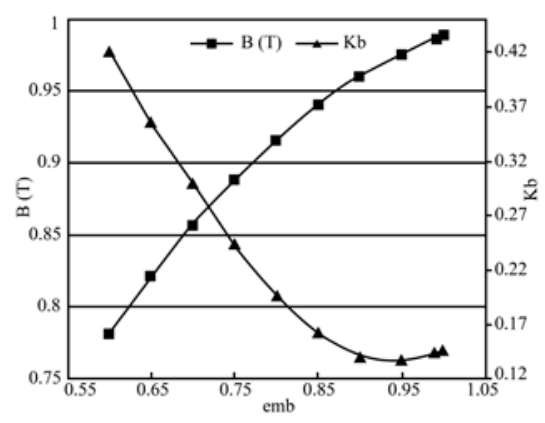

FIGURE VII. EFFECT OF POLE ARC COEFFICIENT ON AIR GAP MAGNETIC FLUX

\section{5) Magnetization Angle}

For Halbach motor, the angle of main pole magnetization direction and auxiliary pole magnetization direction is magnetization angle. Changing prototype motor magnetization angle, which was respectively equal to $5 \mathrm{deg}, 10 \mathrm{deg}, 15 \mathrm{deg}$, 20deg, 30deg, 35deg, 40deg, 45deg, 50deg, the simulation results were shown in Figure 9. Thus with magnetization angle increases the fundamental amplitude of air gap magnetic flux increases slightly and then decreases, and distortion ratio first decreases then increases, and reaches the minimum about $35 \mathrm{deg} \sim 45 \mathrm{deg}$, which is a reasonable range of prototype motor magnetization angle.

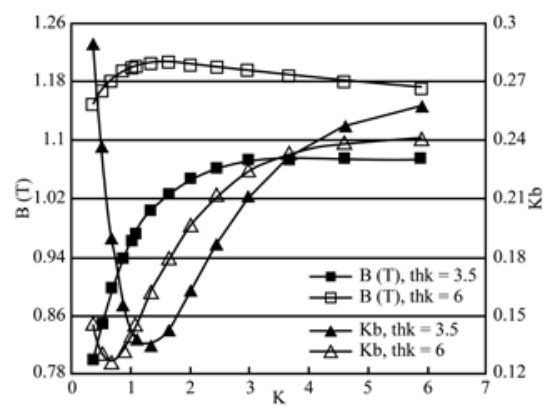

FIGURE VIII. EFFECT OF POLE ANGLE RATIO ON AIR GAP MAGNETIC FLUX

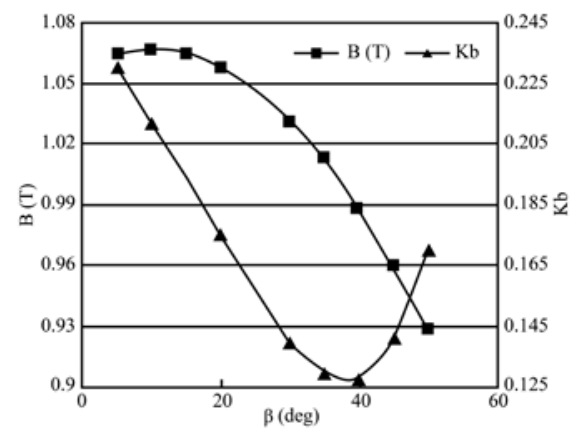

FIGURE IX. EFFECT OF MAGNETIZATION ANGLE ON AIR GAP MAGNETIC FLUX

\section{B. Taguchi Algorithm Optimization}

Taguchi Algorithm is a kind of quality management technology founded by Taguchi Genichi in the early 1950s, and has been widely used in engineering and experiment due to its effectiveness and simplicity. The orthogonal array, a tool of orthogonal experiment as the basis of Taguchi Algorithm, is a 
kind of standardized form developed from the orthogonal Latin square in Combinatorial Mathematics. Only with a partial factor matrix which is a part of all factors, the orthogonal array can make a comparison of any factors at all levels, and reduces the number of tests effectively. In Taguchi Algorithm, the values of the variables to be studied are called levels, and the variables are called factors. In Figure 10, there are 3 variables to be optimized, if each variable has 3 possible values, then common traversal algorithms need to explore $3^{3}=27$ possibilities, while the $\mathrm{L}_{9}\left(3^{3}\right)$ orthogonal array used in Taguchi Algorithm only need 9 tests, hence the workload is greatly reduced. Obviously this gap will be dramatically widen with the rising of factors and levels.

Orthogonal array is actually a direct optimization algorithm, which is different from general direct optimization algorithms that the points must be laid out according to orthogonal array. Zhang [24] pointed out that there are two advantages in orthogonal array, one is uniform dispersion because the dispersion of orthogonal array is higher than that of random distribution. When the dimensions are small the optimization efficiency of orthogonal array is almost similar with random distribution. But when the dimensions are large, the optimization efficiency of the orthogonal array is significantly improved. The other is comparability of uniformity, and for each factor the function value is calculated by the orthogonal array, and the optimum combination can be deduced by the main effect diagram, which provides important information for the next selection.

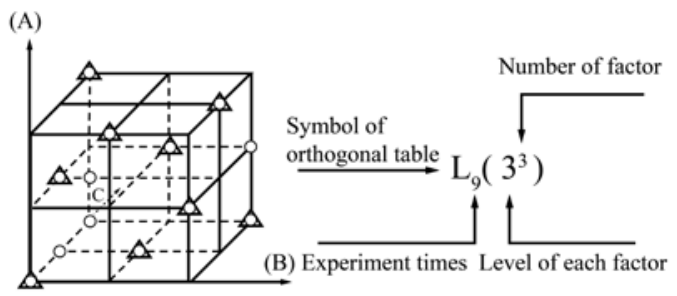

FIGURE X. ORTHOGONAL POINTS AND ORTHOGONAL ARRAY SYMBOL

In order to determine the possible range of the optimum parameters quickly in the first round, for each factor we choose more levels to test, so $\mathrm{L}_{25}\left(5^{5}\right)$, a 5 factors 5 levels orthogonal array is applied. Processed by Minitab16 software, the main factor effect of results was shown in Figure 11. From which we can see that the optimum of each parameter was included in the optimization interval which is determined above. Therefore, $\mathrm{L}_{16}\left(4^{4}\right)$ orthogonal table was selected to complete the following tests which is 4 factors and 4 levels, and reduced the workload significantly.

After 5 rounds of 89 iterations, the distribution of all points objective function values in each round of test was shown in Figure 12, furthermore the air gap magnetic flux fundamental amplitude and distortion ratio of experiment optimum and prediction optimum were shown in Table 2. It is easy to find out that the total optimum of all 5 rounds of experiments is the experiment optimum of the fifth round, and that is ,cost $=0.1268$, $\mathrm{Kb}=12.1812 \%$, B $(\mathrm{T})=0.8720$. In all 5 rounds of experiments, the fluctuation of result in first round tests is very large, but it reduces significantly in the following rounds, and a cross phenomenon is observed. It shows the efficiency of the algorithm is quite high to determine the approximate range of optimum in the initial stage of optimization, but in the following stage the efficiency is quite low in further approximation to the global optimum.

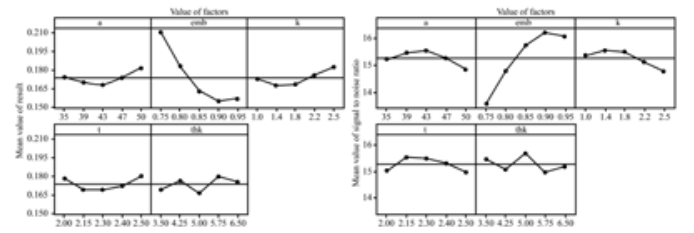

FIGURE XI. MAIN FACTOR EFFECT OF THE FIRST ROUND OPTIMIZATION

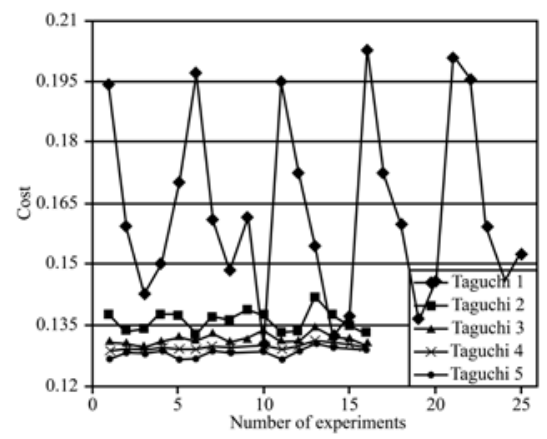

FIGURE XII. DISTRIBUTION OF OBJECTIVE FUNCTION VALUE IN EACH ROUND

TABLE II. EXPERIMENT AND PREDICTION OPTIMUM IN EACH ROUND

\begin{tabular}{|c|c|c|c|c|c|c|c|c|c|c|}
\hline $\begin{array}{l}\text { Ro } \\
\text { un } \\
\text { d }\end{array}$ & $\begin{array}{c}\mathrm{Nu} \\
\text { mbe } \\
\text { r of } \\
\text { exp } \\
\text { eri } \\
\text { men } \\
\text { ts }\end{array}$ & Type & $\begin{array}{l}\text { B } \\
\text { (d } \\
\text { eg } \\
\text { ) }\end{array}$ & $\begin{array}{c}\mathrm{e} \\
\mathrm{m} \\
\mathrm{b}\end{array}$ & $\mathrm{k}$ & $\begin{array}{c}\mathrm{T} \\
(\mathrm{m} \\
\mathrm{m})\end{array}$ & $\begin{array}{c}\text { Th } \\
\mathrm{k} \\
(\mathrm{m} \\
\mathrm{m})\end{array}$ & $\begin{array}{c}\text { Cos } \\
\mathrm{t}\end{array}$ & $\begin{array}{l}\mathrm{Kb} \\
(\%)\end{array}$ & $\mathrm{B}(\mathrm{T})$ \\
\hline \multirow[t]{2}{*}{1} & \multirow[t]{2}{*}{25} & $\begin{array}{c}\text { Expe } \\
\text { rime } \\
n t\end{array}$ & $\begin{array}{c}39 \\
.0\end{array}$ & $\begin{array}{c}0 . \\
95\end{array}$ & $\begin{array}{l}1 . \\
00\end{array}$ & $\begin{array}{c}2.1 \\
5\end{array}$ & $\begin{array}{c}5.0 \\
0\end{array}$ & $\begin{array}{c}0.1 \\
303\end{array}$ & $\begin{array}{l}12.3 \\
212\end{array}$ & $\begin{array}{c}0.88 \\
61\end{array}$ \\
\hline & & $\begin{array}{l}\text { Predi } \\
\text { ction }\end{array}$ & $\begin{array}{l}43 \\
.0\end{array}$ & $\begin{array}{c}0 . \\
90\end{array}$ & $\begin{array}{l}1 . \\
40\end{array}$ & $\begin{array}{c}2.1 \\
5\end{array}$ & $\begin{array}{c}5.0 \\
0\end{array}$ & $\begin{array}{c}0.1 \\
335\end{array}$ & $\begin{array}{l}12.5 \\
113\end{array}$ & $\begin{array}{c}0.87 \\
23\end{array}$ \\
\hline \multirow[t]{2}{*}{2} & \multirow[t]{2}{*}{16} & $\begin{array}{c}\text { Expe } \\
\text { rime } \\
\text { nt }\end{array}$ & $\begin{array}{l}45 \\
.0\end{array}$ & $\begin{array}{c}0 . \\
93\end{array}$ & $\begin{array}{l}1 . \\
20\end{array}$ & $\begin{array}{c}2.2 \\
0\end{array}$ & $\begin{array}{c}5.0 \\
0\end{array}$ & $\begin{array}{c}0.1 \\
326\end{array}$ & $\begin{array}{c}12.4 \\
211\end{array}$ & $\begin{array}{c}0.85 \\
91\end{array}$ \\
\hline & & $\begin{array}{l}\text { Predi } \\
\text { ction }\end{array}$ & $\begin{array}{l}42 \\
.0 \\
\end{array}$ & $\begin{array}{c}0 . \\
90 \\
\end{array}$ & $\begin{array}{l}1 . \\
20 \\
\end{array}$ & $\begin{array}{c}2.2 \\
0 \\
\end{array}$ & $\begin{array}{c}5.0 \\
0 \\
\end{array}$ & $\begin{array}{l}0.1 \\
327 \\
\end{array}$ & $\begin{array}{l}12.4 \\
312 \\
\end{array}$ & $\begin{array}{c}0.85 \\
89 \\
\end{array}$ \\
\hline \multirow[t]{2}{*}{3} & \multirow[t]{2}{*}{16} & $\begin{array}{c}\text { Expe } \\
\text { rime } \\
n t\end{array}$ & $\begin{array}{l}40 \\
.0\end{array}$ & $\begin{array}{c}0 . \\
91\end{array}$ & $\begin{array}{l}1 . \\
20\end{array}$ & $\begin{array}{c}2.2 \\
0\end{array}$ & $\begin{array}{c}5.1 \\
0\end{array}$ & $\begin{array}{c}0.1 \\
296\end{array}$ & $\begin{array}{l}12.3 \\
013\end{array}$ & $\begin{array}{c}0.87 \\
34\end{array}$ \\
\hline & & $\begin{array}{l}\text { Predi } \\
\text { ction }\end{array}$ & $\begin{array}{l}40 \\
.0 \\
\end{array}$ & $\begin{array}{c}0 . \\
92 \\
\end{array}$ & $\begin{array}{c}1 . \\
10\end{array}$ & $\begin{array}{c}2.2 \\
0 \\
\end{array}$ & $\begin{array}{c}5.1 \\
0 \\
\end{array}$ & $\begin{array}{c}0.1 \\
295 \\
\end{array}$ & $\begin{array}{l}12.2 \\
440 \\
\end{array}$ & $\begin{array}{c}0.87 \\
35 \\
\end{array}$ \\
\hline \multirow[t]{2}{*}{4} & \multirow[t]{2}{*}{16} & $\begin{array}{c}\text { Expe } \\
\text { rime } \\
n t\end{array}$ & $\begin{array}{c}39 \\
.0\end{array}$ & $\begin{array}{c}0 . \\
91\end{array}$ & $\begin{array}{l}1 . \\
04\end{array}$ & $\begin{array}{c}2.1 \\
9\end{array}$ & $\begin{array}{c}5.0 \\
4\end{array}$ & $\begin{array}{c}0.1 \\
287\end{array}$ & $\begin{array}{l}12.2 \\
293\end{array}$ & $\begin{array}{c}0.86 \\
97\end{array}$ \\
\hline & & $\begin{array}{l}\text { Predi } \\
\text { ction }\end{array}$ & $\begin{array}{l}39 \\
.0\end{array}$ & $\begin{array}{l}0 . \\
92 \\
\end{array}$ & $\begin{array}{l}1 . \\
04\end{array}$ & $\begin{array}{c}2.1 \\
9\end{array}$ & $\begin{array}{c}5.0 \\
4 \\
\end{array}$ & $\begin{array}{c}0.1 \\
276 \\
\end{array}$ & $\begin{array}{l}12.2 \\
254\end{array}$ & $\begin{array}{c}0.87 \\
14\end{array}$ \\
\hline \multirow[t]{2}{*}{5} & \multirow[t]{2}{*}{16} & $\begin{array}{c}\text { Expe } \\
\text { rime } \\
n t\end{array}$ & $\begin{array}{c}38 \\
.0\end{array}$ & $\begin{array}{c}0 . \\
91\end{array}$ & $\begin{array}{c}1 . \\
01\end{array}$ & $\begin{array}{c}2.1 \\
8\end{array}$ & $\begin{array}{c}5.0 \\
2\end{array}$ & $\begin{array}{c}0.1 \\
268\end{array}$ & $\begin{array}{l}12.1 \\
812\end{array}$ & $\begin{array}{c}0.87 \\
20\end{array}$ \\
\hline & & $\begin{array}{l}\text { Predi } \\
\text { ction }\end{array}$ & $\begin{array}{c}38 \\
.5\end{array}$ & $\begin{array}{c}0 . \\
91\end{array}$ & $\begin{array}{l}1 . \\
01\end{array}$ & $\begin{array}{c}2.1 \\
8\end{array}$ & $\begin{array}{c}5.0 \\
6\end{array}$ & $\begin{array}{c}0.1 \\
270\end{array}$ & $\begin{array}{l}12.1 \\
985\end{array}$ & $\begin{array}{c}0.87 \\
34\end{array}$ \\
\hline
\end{tabular}




\section{Genetic Algorithm Optimization}

Genetic Algorithm is a global optimization algorithm essentially proposed by Holland in 1970s, which simulates The Survival of The Fittest in nature and applies Darwin's theory of biological evolution in optimization. The problem space is mapped to the code space via encode operation, after that the biological genetic evolution mechanism is simulated by selection, mating, mutation and iteration in the code space. The solution of the problem is obtained after inverse mapping from code space back to original space. The flow chart of the algorithm is shown in Figure 13. Genetic algorithm is an adaptive stochastic parallel algorithm which is good at global search but not local search. The motor optimization is a kind of complicated nonlinear problem, while Genetic Algorithm is suitable for solving this kind of problem [25]. But it is necessary to deal with the initial group design, fitness function design, encoding and decoding, genetic operation and a series of specific issues.

The prototype motor are optimized by Genetic Algorithm, and the iteration process is shown in Figure 14.The optimum is obtained after 315 iterations which is shown in Table 3, i.e., cost $=0.1359, \quad K b=13.0395 \%, \quad B \quad(T)=0.8309$. Genetic Algorithm simulates the process of biological evolution, especially introduces mutation operation into optimization process, so it is advantageous to jump out of local optima into a wider region to find out the global optimum. But hop is easy to occur in this algorithm, even in the later stage of optimization. The damage caused by hop is great when the hop is close to global optimum, so the efficiency in the later stage of optimization is quite low.

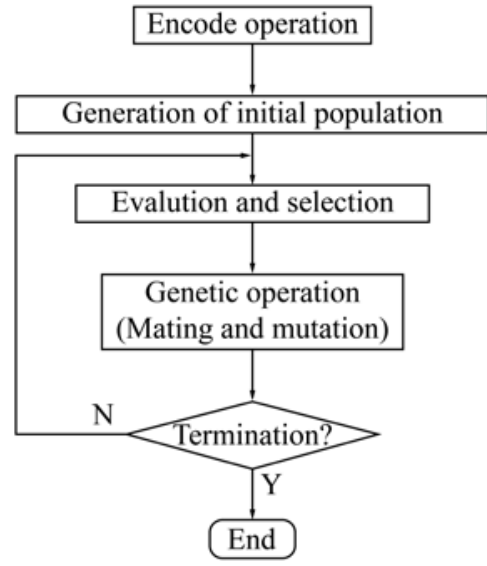

FIGURE XIII. FFLOW CHART OF GENETIC ALGORITHM

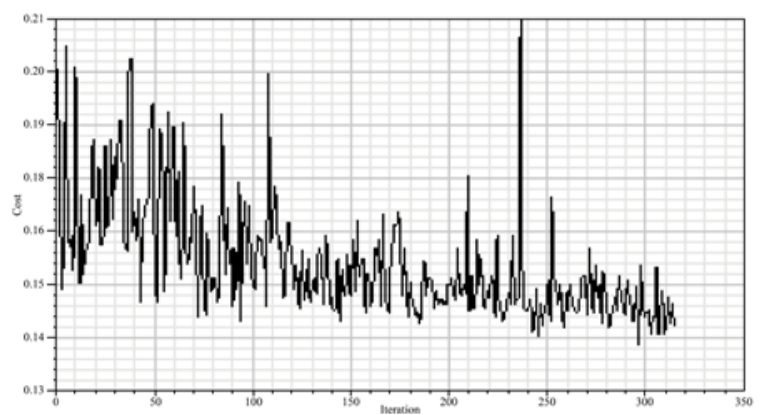

FIGURE XIV. ITERATIVE PROCESS OF GENETIC ALGORITHM
TABLE III. OPTIMA OF GENETIC ALGORITHM

\begin{tabular}{|c|c|c|c|c|c|c|c|c|}
\hline $\begin{array}{c}\text { Param } \\
\text { eters }\end{array}$ & $\mathrm{a}(\mathrm{deg})$ & $\begin{array}{c}\text { em } \\
\mathrm{b}\end{array}$ & k & $\begin{array}{c}\mathrm{t}(\mathrm{m} \\
\mathrm{m})\end{array}$ & $\begin{array}{c}\text { thk(m } \\
\mathrm{m})\end{array}$ & Cost & $\begin{array}{c}\mathrm{Kb}(\% \\
)\end{array}$ & $\begin{array}{c}\mathrm{B} \\
(\mathrm{T})\end{array}$ \\
\hline $\begin{array}{l}\text { Optim } \\
\text { um }\end{array}$ & 38.48 & $\begin{array}{c}0.9 \\
2\end{array}$ & $\begin{array}{c}1.0 \\
3\end{array}$ & 2.36 & 4.81 & $\begin{array}{c}0.13 \\
59\end{array}$ & $\begin{array}{c}13.03 \\
95\end{array}$ & $\begin{array}{c}0.83 \\
09\end{array}$ \\
\hline
\end{tabular}

\section{Pattern Search Algorithm Optimization}

For some engineering problems whose objective functions are too complex to be expressed or calculate the derivative, so a direct optimization algorithm was developed not involving derivative. In this algorithm, the basis for selecting a new iteration point was only the value of objective function [26]. Pattern Search was proposed by Hooke and Jeeves in 1961[27], which is one kind of direct algorithms, and the convergence of the algorithm in nonlinear unconstrained optimization problems was demonstrated by Torczon in 1997[28].

Pattern Search starts from the reference point to search for a better point. If such a point is found, then it is selected as a base point, and a new round of search proceeded along the direction from the reference point to the base point. The Vector from the reference point to the base point is called pattern. Then the pattern move is carried out, the starting point of the pattern is the base point, and the end point is the new reference point. Hence search and pattern move are carried out alternately until the iteration point is gradually close to the optimum. The alternation of detection search and pattern move is showed in Figure 3.

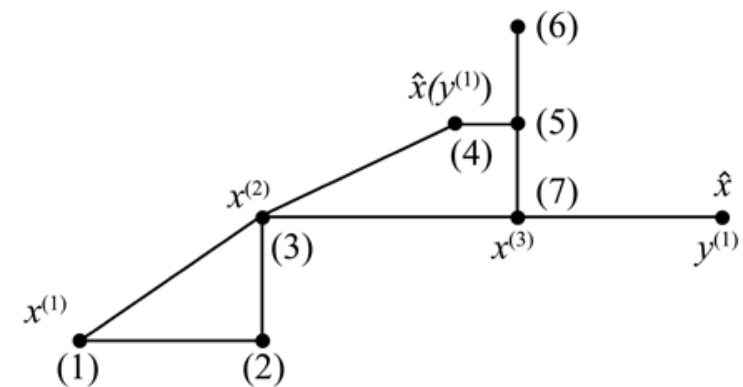

FIGURE XV. ALTERNATION OF THE SEARCH AND THE PATTERN
MOVE

Pattern Search Algorithm is slow, but it is simple, especially it is easy to realize automatic optimization using computer program without derivative. Using this algorithm Ignizio solved a nonlinear programming problem and the results are satisfactory [29]. Polak and Céa studied the convergence of Pattern Search Algorithm. Polak found for the iterative sequence $\left\{\mathrm{x}_{\mathrm{k}}\right\}$, Pattern Search Algorithm only produced a limited number of intermediate points before the step size was decreased, which demonstrated that any intermediate point would not block the iterative process, and the search process was bound to converge on the global stationary point $\mathrm{x}^{*}[30]$. On this basis, Céa proved the global convergence of Pattern Search Algorithm [31].

Pattern Search algorithm was used to optimize the prototype motor, after 112 iterations, optima were obtained as shown in Figure 16 and Table 4, namely cost $=0.1362$, $\mathrm{Kb}=13.9196 \%$, $\mathrm{B}(\mathrm{T})=0.8303$. It can be seen from the 
optimization process, because the initial point 1 , itself is better whose distance to the optimum is smaller, the quality of the optimization results is relatively better. Whereas the initial point2 itself is poorer whose distance to the optimum is greater, the quality of the optimization results is relatively poorer. Because the optimization algorithm and optimization parameters were same, so the differences between both optimization results were caused by the different initial points. When the two initial points are far apart, the Pattern Search Algorithm will converge to two different local optima. Hence it shows that the local search ability of the algorithm is very strong, but the search scope is limited near the initial point, so there is a great correlation between the optimization results and the selection of the initial point.

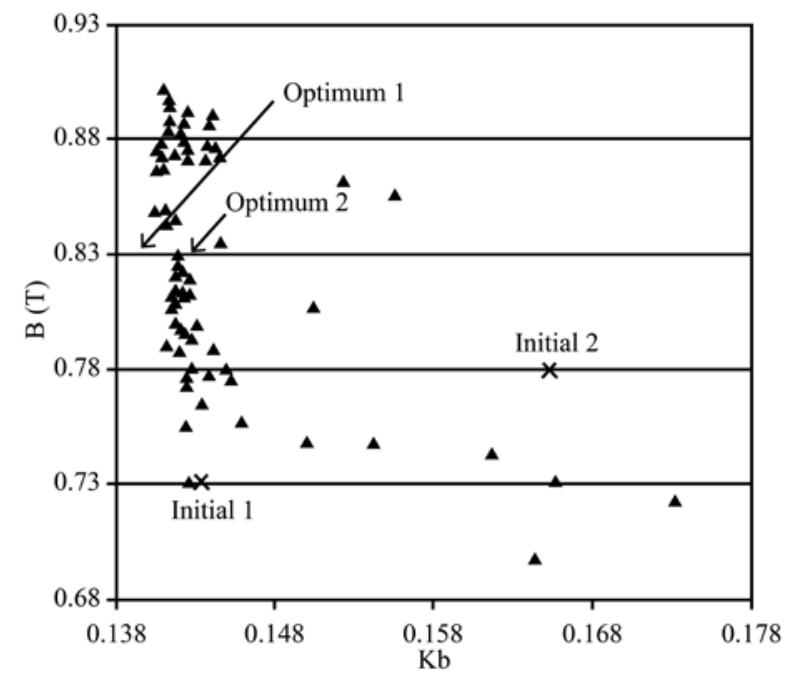

FIGURE XVI. FUNDAMENTAL AMPLITUDE AND DISTORTION RATIO CORRESPONDING TO EVERY ITERATION POINT

TABLE IV. OPTIMA OF PATTERN SEARCH ALGORITHM

\begin{tabular}{|c|c|c|c|c|c|c|c|c|}
\hline $\begin{array}{c}\text { Paramete } \\
\text { rs } \\
\end{array}$ & $\begin{array}{c}a(\operatorname{deg} \\
)\end{array}$ & $\begin{array}{c}\text { em } \\
b\end{array}$ & $\mathrm{k}$ & $\begin{array}{c}\mathrm{t}(\mathrm{mm} \\
)\end{array}$ & $\begin{array}{c}\text { thk(m } \\
\mathrm{m})\end{array}$ & Cost & $\mathrm{Kb}(\%)$ & $\mathrm{B}(\mathrm{T})$ \\
\hline Initial 1 & $\begin{array}{c}45.0 \\
0 \\
\end{array}$ & $\begin{array}{c}0.8 \\
7 \\
\end{array}$ & $\begin{array}{c}1.0 \\
0 \\
\end{array}$ & 2.00 & 3.50 & $\begin{array}{c}0.155 \\
1 \\
\end{array}$ & $\begin{array}{c}16.559 \\
9 \\
\end{array}$ & $\begin{array}{c}0.732 \\
3 \\
\end{array}$ \\
\hline $\begin{array}{c}\text { Optimum } \\
1 \\
\end{array}$ & $\begin{array}{c}36.6 \\
2 \\
\end{array}$ & $\begin{array}{c}0.9 \\
0\end{array}$ & $\begin{array}{c}1.0 \\
0\end{array}$ & 2.20 & 4.75 & $\begin{array}{c}0.136 \\
2 \\
\end{array}$ & $\begin{array}{c}13.919 \\
6 \\
\end{array}$ & $\begin{array}{c}0.830 \\
3 \\
\end{array}$ \\
\hline Initial 2 & $\begin{array}{c}50.0 \\
0 \\
\end{array}$ & $\begin{array}{c}0.7 \\
0 \\
\end{array}$ & $\begin{array}{c}1.0 \\
0 \\
\end{array}$ & 1.00 & 3.00 & $\begin{array}{c}0.305 \\
9 \\
\end{array}$ & $\begin{array}{c}18.094 \\
0 \\
\end{array}$ & $\begin{array}{c}0.772 \\
5 \\
\end{array}$ \\
\hline $\begin{array}{c}\text { Optimum } \\
2 \\
\end{array}$ & $\begin{array}{c}39.5 \\
0 \\
\end{array}$ & $\begin{array}{c}0.9 \\
0 \\
\end{array}$ & $\begin{array}{c}1.0 \\
0 \\
\end{array}$ & 1.30 & 3.25 & $\begin{array}{c}0.154 \\
8 \\
\end{array}$ & $\begin{array}{c}16.528 \\
8 \\
\end{array}$ & $\begin{array}{c}0.830 \\
9 \\
\end{array}$ \\
\hline
\end{tabular}

\section{NOvel Hybrid AlgorithmS}

From the results above, it can be seen that the global search ability of Taguchi Algorithm and Genetic Algorithm is relatively strong, and the global optimum can be quickly approximated after a few iterations, but the efficiency of the two algorithms is not ideal in the later stage of optimization, which is a significant disadvantage. The diversity of individuals has been lost because the difference between most individuals and optima is quite small. On the contrary, the Pattern Search Algorithm has strong local search ability, but the result of the optimization is greatly affected by the initial point. Generally speaking, the more closer initial point to the optimum, the better the optimization is. So it is possible to combine Pattern Search with these two algorithms to form two novel hybrid optimization algorithms.

\section{A. Taguchi-Pattern Search Hybrid Algorithm Optimization}

In Taguchi-Pattern Search Hybrid Algorithm, Taguchi Algorithm was employed to carry out a multi-round global search to find a quite good point at first, which was selected as the initial point. After the optimization efficiency significantly reduced, Pattern Search Algorithm was performed to further the optimization until finding global optimum. In this experiment, the optima of Taguchi Algorithm in Section $B$ were directly selected as initial points, Pattern Search Algorithm was implemented in same optimization parameters. It can be seen from Table 5 that distortion ratio of air gap magnetic flux reduced from $12.1812 \%$ to $12.1368 \%$. The optimization is improved but not significant, while more significantly compared with the results of Pattern Search from prototype motor directly.

TABLE V. OPTIMA OF TAGUCHI-PATTERN SEARCH HYBRID ALGORITHM

\begin{tabular}{|c|c|c|c|c|c|c|c|c|}
\hline $\begin{array}{c}\text { Paramet } \\
\text { ers }\end{array}$ & $\begin{array}{l}\text { a(de } \\
\text { g) }\end{array}$ & $\begin{array}{c}\mathrm{em} \\
\mathrm{b}\end{array}$ & $\mathrm{k}$ & $\begin{array}{l}\mathrm{t}(\mathrm{m} \\
\mathrm{m})\end{array}$ & $\begin{array}{c}\text { thk }(\mathrm{m} \\
\mathrm{m})\end{array}$ & Cost & $\begin{array}{c}\mathrm{Kb}(\% \\
)\end{array}$ & $\mathrm{B}(\mathrm{T})$ \\
\hline Taguchi & 38.0 & 0.9 & 1.0 & 2.18 & 5.02 & 0.126 & 12.18 & 0.872 \\
\hline $\begin{array}{c}\text { Optimu } \\
\text { m }\end{array}$ & 0 & 1 & 1 & & & 8 & 12 & 0 \\
\hline $\begin{array}{c}\text { Pattern } \\
\text { Search } \\
\text { Optimu } \\
\text { m }\end{array}$ & $\begin{array}{c}36.6 \\
2\end{array}$ & $\begin{array}{c}0.9 \\
0\end{array}$ & $\begin{array}{c}1.0 \\
0\end{array}$ & 2.20 & 4.75 & $\begin{array}{c}0.136 \\
2\end{array}$ & $\begin{array}{c}13.91 \\
96\end{array}$ & $\begin{array}{c}0.830 \\
3\end{array}$ \\
\hline $\begin{array}{l}\text { Taguchi- } \\
\text { PS } \\
\text { Optimu } \\
\text { m }\end{array}$ & $\begin{array}{c}37.4 \\
4\end{array}$ & $\begin{array}{c}0.9 \\
1\end{array}$ & $\begin{array}{c}1.0 \\
1\end{array}$ & 2.28 & 5.33 & $\begin{array}{c}0.125 \\
3\end{array}$ & $\begin{array}{c}12.13 \\
68\end{array}$ & $\begin{array}{c}0.877 \\
3\end{array}$ \\
\hline
\end{tabular}

TABLE VI. OPTIMA OF GENETIC-PATTERN SEARCH HYBRID ALGORITHM

\begin{tabular}{|c|c|c|c|c|c|c|c|c|}
\hline $\begin{array}{c}\text { Paramet } \\
\text { ers }\end{array}$ & $\begin{array}{c}\mathrm{a}(\mathrm{de} \\
\mathrm{g})\end{array}$ & $\begin{array}{c}\text { em } \\
\mathrm{b}\end{array}$ & $\mathrm{k}$ & $\begin{array}{c}\mathrm{t}(\mathrm{m} \\
\mathrm{m})\end{array}$ & $\begin{array}{c}\text { thk(m } \\
\mathrm{m})\end{array}$ & $\begin{array}{c}\text { Cost } \\
\text { Kb(\% } \\
)\end{array}$ & $\mathrm{B}(\mathrm{T})$ \\
\hline $\begin{array}{c}\text { Genetic } \\
\text { Optimu } \\
\mathrm{m}\end{array}$ & $\begin{array}{c}38.4 \\
8\end{array}$ & $\begin{array}{c}0.9 \\
2\end{array}$ & $\begin{array}{c}1.0 \\
3\end{array}$ & 2.36 & 4.81 & $\begin{array}{c}0.135 \\
9\end{array}$ & $\begin{array}{c}13.03 \\
95\end{array}$ & $\begin{array}{c}0.830 \\
9\end{array}$ \\
\hline $\begin{array}{c}\text { Genetic } \\
\text {-PS }\end{array}$ & $\begin{array}{c}38.4 \\
\text { Optimu }\end{array}$ & 0.9 & 1.0 & 2.41 & 5.56 & 0.125 & 12.14 & 0.871 \\
$\mathrm{~m}$ & & 2 & 0 & & & 8 & 02 & 5 \\
\hline
\end{tabular}

\section{B. Genetic-Pattern Search Hybrid Algorithm Optimization}

In Genetic-Pattern Search Hybrid Algorithm, Genetic Algorithm was carried out to find local optima, which is same to Taguchi-Pattern Search Hybrid Algorithm in following steps. The optima of Genetic Algorithm in Section $B$ were selected as the initial point, after that the Pattern Search Algorithm was implemented to further the optimization. From Table 6, it can be seen that the optimization effect is obvious, and the distortion ratio of the air gap magnetic flux is reduced from $13.0395 \%$ to $12.1402 \%$. This shows that the effect of Genetic Algorithm used in permanent magnet motor optimization is relatively significant, but there is still a possibility of improvement, and the optimization effect is improved obviously using Genetic-Pattern Search Hybrid Algorithm. 


\section{CONCLUSIONS}

It can be seen from the comparison of these experiments results shown in Figure 17, Figure 18 and Tab.6, for the optimization of permanent magnet motor, starting from a reasonable prototype motor, all above algorithms are effectively. The results of Pattern Search Algorithm and Genetic Algorithm are quite close, but Pattern Search Algorithm is sensitive to initial point and easy to converge to local optimum. Genetic algorithm is easy to hop in the later stage, so the optimization efficiency is low and difficult to accurately approximate the global optimum.

The results are relatively close in Taguchi Algorithm, Taguchi-Pattern Search Hybrid Algorithm and Genetic-Pattern Search Hybrid Algorithm, and compared to Pattern Search Algorithm and Genetic Algorithm, these three algorithms are better. The accuracy of Taguchi algorithm in approaching the global optimum is not good, and similar with Genetic Algorithm. Both hybrid algorithms combine the advantages of the original algorithms, so a large number of low efficient calculations in the later stage of optimization can be avoided in the premise of good accuracy. Therefore, according to the requirements, combining different algorithms, playing their strengths and avoiding or limiting their shortcomings as far as possible, ,it is possible to create better novel algorithm in the optimization of permanent magnet motor.

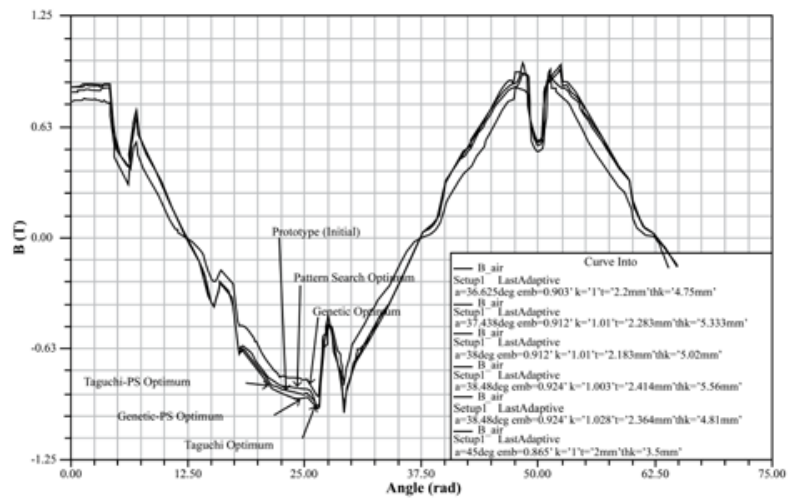

FIGURE XVII. WAVEFORM COMPARISON OF OPTIMA IN DIFFERENT ALGORITHMS

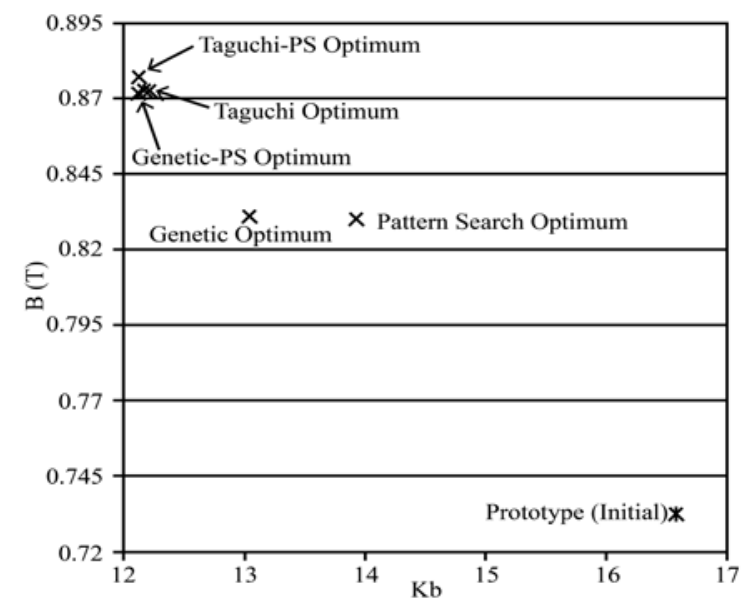

FIGURE XVIII. COMPARISON OF DIFFERENT OPTIMA IN DIFFERENT ALGORITHMS
TABLE VII. COMPARISON OF DIFFERENT OPTIMA IN DIFFERENT ALGORITHMS

\begin{tabular}{ccccccccc}
\hline Parameters & $\begin{array}{c}\beta(\mathrm{de} \\
\mathrm{g})\end{array}$ & $\begin{array}{c}\mathrm{em} \\
\mathrm{b}\end{array}$ & $\mathrm{k}$ & $\begin{array}{c}\mathrm{t}(\mathrm{m} \\
\mathrm{m})\end{array}$ & $\begin{array}{c}\text { thk }) \mathrm{m} \\
\mathrm{m})\end{array}$ & $\begin{array}{c}\text { Cost } \\
\mathrm{Kb}(\%\end{array}$ & $\begin{array}{c}\mathrm{B} \\
(\mathrm{T})\end{array}$ \\
\hline Prototype)In & 45.0 & 0.8 & 1.0 & 2.00 & 3.50 & 0.15 & 16.55 & 0.73 \\
itial) & 0 & 7 & 0 & & & 51 & 99 & 23 \\
Taguchi & 38.0 & 0.9 & 1.0 & 2.18 & 5.02 & 0.12 & 12.18 & 0.87 \\
Optimum & & 1 & 1 & & 68 & 12 & 20 \\
Genetic & 38.4 & 0.9 & 1.0 & 2.36 & 4.81 & 0.13 & 13.03 & 0.83 \\
Optimum & 8 & 2 & 3 & & & 59 & 95 & 09 \\
Pattern & 36.6 & 0.9 & 1.0 & 2.20 & 4.75 & 0.13 & 13.91 & 0.83 \\
Search & 2 & 0 & 0 & & & 62 & 96 & 03 \\
Optimum & & & & & & & & \\
Taguchi-PS & 37.4 & 0.9 & 1.0 & 2.28 & 5.33 & 0.12 & 12.13 & 0.87 \\
Optimum & 4 & 1 & 1 & & & 53 & 68 & 73 \\
Genetic -PS & 38.4 & 0.9 & 1.0 & 2.41 & 5.56 & 0.12 & 12.14 & 0.87 \\
Optimum & 8 & 2 & 0 & & & 58 & 02 & 15 \\
\hline
\end{tabular}

\section{REFERENCES}

[1] W. Zhao, T. A. Lipo, and B. I. Kwon, "Comparative study on novel dual stator radial flux and axial flux permanent magnet motors with ferrite magnets for traction application," IEEE Transactions on Magnetics, vol. 50, pp.1-4, December 2014.

[2] K.Y. Yoon and B. I. Kwon, "Optimal Design of a New Interior Permanent Magnet Motor Using a Flared-Shape Arrangement of Ferrite Magnets," IEEE Transactions on Magnetics,vol.52, pp.1-4, February 2016.

[3] A. A. Novotny and J. Sokolowski, "Topological derivatives in shape optimization," Topological Derivative in Shape Optimization, Springer, Berlin, 2013, pp. 2625-2626.

[4] S. Amstutz and A. Laurain, "A Semi-smooth Newton method for a class of semi-linear optimal control problems with box and volume constraints," Computational Optimization and Applications, vol.56, pp.369-403, 2013.

[5] K. Sturm, "Lagrange method in shape optimization for non-linear partial differential equations: A material derivative free approach," Technical Report 1817, Weierstrass Institute for Applied Analysis and Stochastics, 2013.

[6] D. Goswami and S. Chakraborty, "Differential search algorithm-based parametric optimization of electrochemical micromachining processes," International Journal of Industrial Engineering Computations, vol.5, pp.41-54, 2014.

[7] W. X. Xing, J. X. Xie, "Modern optimization calculation algorithm," Tsinghua University press, Beijing, 2005.

[8] Y. Nyanteh, C. Edrington, S. Srivastava, and D. Cartes, "Application of artificial intelligence to real-time fault detection in permanent magnet synchronous motors ," IEEE Transactions on Industry applications, vol.49, pp.1205-1214, March 2013

[9] A. Laurain, "Global minimizer of the ground state for two phase conductors in low contrast regime," Esaim Control Optimization and Calculus of Variations, vol.20, pp.362-388, March 2014.

[10] S. J. Song, L. F. Ge, and H. C. Liu, "Design of switched reluctance motor and multi objective optimization algorithm," Journal of electric technology, vol.29, pp.197-204, 2014.

[11] P. Gangl and U. Langer, "Topology optimization of electric machines based on topological sensitivity analysis," Computing and Visualization in Science,vol.15, pp.345-354, December 2012.

[12] R. Ilka, A.R. Tilaki, H.A. Alamdari and R. Baghipour, "Design Optimization of Permanent Magnet-Brushless DC Motor using Elitist Genetic Algorithm with Minimum loss and Maximum Power Density," International Journal of Mechatronics, Electrical and Computer Technology, vol.4, pp.1169-1185, 2014.

[13] K. Halbach, "Design of permanent multipole magnets with oriented rare earth cobalt material," Nuclear Instruments and Methods, vol.169, pp.1-10, February 1980.

[14] G. Q. Song and C. H. Zhao, "Study of Halbach Array PM Machines," Electric Machines \& Control Application, vol.35, pp.12-17, 2008. 
[15] Z. Q. Zhu and D. Howe, "Halbach permanent magnet machines and application : a review," IEEE Proceedings of Electric power applications, vol.148, pp.299-308, July 2001.

[16] G. Zhou, X. L. Huang, Q. B. Zhou and M. Fu, " The Applications of the Halbach Permanent Magnet Array : a Review," Small \& Special Electrical Machines, vol.36, pp.22-26, 2008.

[17] J. J. Fan, J. H. Wu, "Analytical Solution and Analysis of Airgap Magnetic Field of PMSM With Partition-between-poles Halbach Magnet Considering Effect of Slotting," Proceedings of the Chinese Society for Electrical Engineering, vol.30, pp.98-105, April 2010.

[18] Y. Shen and Z. Q. Zhu, "Analysis of electromagnetic performance of Halbach PM brushless machines having mixed grade and unequal height of magnets ," IEEE Transactions on magnetics, vol.49, pp.1461-1469, November 2012.

[19] S. Sadeghi and L. Parsa, "Multiobjective design optimization of fivephase Halbach array permanent magnet machine, " IEEE Transactions on magnetics, Vol.47, pp.1658-1666, January 2011.

[20] H. J. Kim, D. Y. Kim, and J. P. Hong, "Structure of Concentrated-FluxType Interior Permanent Magnet Synchronous Motors Using Ferrite Permanent Magnets," IEEE Transactions on Magnetics, vol.50, pp.1-4, December 2014.

[21] S. Q. Shah, T. A. Lipo, and K. Byung, "Modeling of novel permanent magnet pole shape SPM motor for reducing torque pulsation," IEEE Transactions on magnetics, vol.48, pp.4626-4629, October 2012.

[22] Y. Shen, and Z. Q. Zhu, "Analysis of electromagnetic performance of Halbach PM brushless machines having mixed grade and unequal height of magnets,"IEEE Transactions on magnetics, vol.49, pp.1461-1469, November 2013.

[23] S. Frei, and T. Richter, "A Locally Modified Parametric Finite Element Method for Interface Problems," Siam Journal on Numerical Analysis, vol.52, pp.2315-2334, September 2014.

[24] L. Q. Zhang, "The comparison of orthogonal design and uniform design," Journal of Applied Statistics and Management, vol.1, pp.25-30, 1995.

[25] A.R. Tilaki, H.A. Alamdari , R. Baghipour, and L. Reza, "Design Optimization of Permanent Magnet-Brushless DC Motor using Elitist Genetic Algorithm with Minimum loss and Maximum Power Density," International Journal of Mechatronics, Electrical and Computer Technology, vol.4, pp.1169-1185, 2014.

[26] [M. Miloš and R. Miroslav, "Optimization of machining processes using pattern search algorithm," International Journal of Industrial Engineering Computations, vol.5, pp.223-234, 2014.

[27] R. Hooke, and T. A. Jeeves, "Direct search solution of numerical and statistical problems, " Journal of the Acm, vol.8, pp.212-229, April 1961.

[28] V. Torczon, " On the convergence of Pattern Search algorithms," Siam Journal on Optimization, vol.7, pp.1-25, 1997.

[29] J. P. Ignizio, "Goal programming and extensions", Lexington Books, 1976.

[30] E. D. Dolan and M. Lewis, "On the local convergence of Pattern Search," Institute for Computer Applications in Science and Engineering(ICASE),2000.

[31] J. Céa, S. Garreau, and P. Guillaume, "The shape and topological optimization connection," Computer Methods in Applied Mechanics \& Engineering, vol.188, pp.713-726,August 2000. 